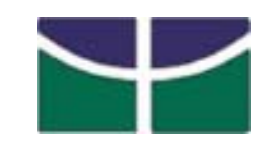

Universidade de Brasília - UnB

Centro de Excelência em Turismo - CET

Curso de Pós-graduação(lato-sensu) em "Qualidade em Alimentos"

Profa. Orientadora: Elizabeth Maria Talá de Souza

\title{
A Validade da Suplementação de Creatina e suas Limitações
}

Luciana Mendoza Cidade

Brasília/DF, Janeiro de 2003. 
LUCIANA MENDOZA CIDADE

\section{A Validade da Suplementação de Creatina e suas Limitações}

Monografia apresentada como requisito para conclusão do curso de especialização (lato-sensu) de "Qualidade em Alimentos" - Centro de Excelência em Turismo - Universidade de Brasília

Profa. Orientadora: Elizabeth Maria Talá

Brasília/DF, Janeiro de 2003 
"Quem julga com a vontade nunca pode julgar bem.

A razão é muito clara: quem julga com entendimento, se entende mal, julga mal; se entende bem, julga bem.

Porém, quem julga com a vontade, ou queira mal, ou queira bem, sempre julga mal; se quer mal, julga como apaixonado, se quer bem, julga como cego."

Pe. Antonio Vieira 
Agradecimentos,

Agradeço a Deus por iluminar os meus caminhos.

À minha família pelo apoio constante.

Ao meu filho (in memorian), meu anjo da guarda.

À professora orientadora Elizabeth Maria Talá de Souza, muito importante para a concretização deste trabalho. 


\section{SUMÁRIO}

1.Introdução 1

2.Metabolismo 3

2.1 Componentes energéticos da dieta 4

2.1.1 Carboidratos 4

2.1.2 Lipídios 6

2.1.3 Proteínas 8

3.Bioenergética 11

3.1 Atividades Aeróbicas X Atividades Anaeróbicas 12

3.1.1 Sistema Energético ATP-CP 14

3.1.2 Glicólise Anaeróbia 15

3.1.3 Metabolismo Aeróbio 16

3.2 Perfil metabólico dos principais orgãos 17

4.Creatina 18

4.1 Mecanismo de Ação da Creatina 18

4.2 Distribuição da Creatina 21

4.3 Creatina como Suplemento 22

4.3.1 Efeitos Ergogênicos da Suplementação 23

4.3.2 Efeitos Ergolíticos da Suplementação 25

4.3.3 Prática da Suplementação de Creatina 27

5.Recursos da Alimentação 30

6.Conclusão 32

7.Referências Bibliográficas 33 


\section{RESUMO}

Apesar de ser um nutriente natural do organismo ou encontrado em carnes vermelhas e peixes através da alimentação, a creatina na forma de suplemento tem sido utilizada por diversos atletas e freqüentadores de academia, em maior escala, com o intuito de obtenção de um acréscimo de energia e massa muscular. Entretanto, sua eficácia ainda continua em discussão por mais benefícios que demonstre seu mecanismo de ação. Sendo assim, procurou-se analisar, através desse estudo, o papel da creatina no organismo e possíveis efeitos da sua suplementação, destacando também a importância de uma alimentação saudável e treinamento. 


\begin{abstract}
Although creatine to be a natural nutrient of organism or found in animal foods, the creatine supplement has been used for many people to increase strength and muscle mass. However, the supplement eficacy is in discussion and short-term negative effects are unknowed. The study involves a creatine function in organism and possible effects of supplementation in conjunction with physical training and proper nutrition.
\end{abstract}




\section{INTRODUÇÃO}

A nutrição corresponde aos processos gerais de ingestão e conversão de substâncias alimentícias em nutrientes que podem ser utilizados para manter a função orgânica. Quando os nutrientes se apresentam em quantidades ideais para o organismo, a saúde e o bem-estar do indivíduo são maximizados.

Qualquer atividade física implica em dispêndio de energia e, portanto, na recuperação da energia dispersada. Mas essa necessidade de energia depende, principalmente, do esforço dispendido durante a atividade física, considerando-se naturalmente, a situação dos indivíduos quanto ao sexo, tamanho, idade e biotipo, além da duração e do tipo de atividade praticada.

A alimentação bem orientada é fator primordial à saúde do atleta, que vai influenciar na sua capacidade de realização do trabalho físico. Dessa forma, a produção energética do organismo vai depender da qualidade e quantidade de nutrientes apropriados ao esse trabalho físico.

Independente do propósito do exercício, o seu sucesso é determinado por dois fatores principais: a genética e o treinamento, para maximização do potencial genético. Dados os recentes avanços tecnológicos, muitas estratégias de treinamento aplicadas aos atletas de elite têm se tornado disponíveis para atletas competitivos de todos os níveis, incluindo categorias menores, o que os leva a procurar outros métodos para alcançar uma vantagem competitiva. Dentre esses métodos, encontram-se os suplementos dietéticos, amplamente utilizados por atletas à procura de um efeito ergogênico.

Constatando-se isso, verificou-se a necessidade de aprofundar os conhecimentos em torno da suplementação de creatina, mais popular suplemento dietético atualmente comercializado como potencial ergogênico, apesar de ser encontrado naturalmente em vários alimentos, sendo escolhido como tema da monografia “ A Validade da Suplementação de Creatina e suas Limitações” .

O presente trabalho tem como objetivo geral verificar o mecanismo de ação da creatina no organismo e a necessidade de sua utilização suplementada. $E$ como objetivos específicos, pode-se citar: 
- Analisar o papel da creatina na integração metabólica;

- Avaliar possíveis efeitos ergogênicos da suplementação de creatina;

- Verificar efeitos ergolíticos da suplementação de creatina;

- Avaliar a prática da suplementação de creatina no mercado;e

- Destacar fontes dietéticos de creatina.

Como metodologia do trabalho, foi utilizada como técnica essencial a revisão bibliográfica, visando embasamento teórico do assunto abordado de forma explicativa. 


\section{METABOLISMO}

O metabolismo é uma atividade celular altamente coordenada, com propósitos determinados, e na qual cooperam muitos sistemas enzimáticos, com quatro funções específicas:

1. obter energia química pela degradação de nutrientes ricos em energia oriundos do meio ambiente;

2. converter as moléculas dos nutrientes em unidades fundamentais precursoras das macromoléculas celulares;

3. reunir e organizar estas unidades fundamentais em proteínas, ácidos nucléicos e outros componentes celulares;

4. sintetizar e degradar biomoléculas necessárias às funções especializadas das células. ${ }^{6}$

O metabolismo consiste em duas fases: catabolismo e anabolismo.

O catabolismo é a fase degradativa do metabolismo, onde as moléculas orgânicas provenientes do meio ambiente ou dos reservatórios de nutrientes da própria célula são degradados por reações consecutivas em produtos finais menores e mais simples. O catabolismo é acompanhado pela liberação da energia livre inerente à estrutura complexa dessas moléculas, conservada na forma de adenosina trifosfato (ATP) através do acoplamento de reações enzimáticas ou na forma de átomos de hidrogênio ricos em energia transportados pela coenzima nicotinamida adenina dinucleotídeo fosfato em sua forma reduzida NADPH ${ }^{6}$.

Já na segunda via, o anabolismo, também chamado de biossíntese, as pequenas moléculas precursoras são reunidas para formar as grandes macromoléculas componentes das células, como as proteínas e os ácidos nucléicos, o que requer energia livre, feita pela quebra de ATP em ADP e fosfato e de átomos de hidrogênio, fornecidos pelo NADPH . 
Analisando melhor o catabolismo, nota-se que a degradação enzimática de cada um dos principais nutrientes celulares liberadores de energia (carboidratos, proteínas e lipídios) ocorre passo a passo através de reações enzimáticas consecutivas. Existem três estágios principais no catabolismo aeróbico. No primeiro estágio as macromoléculas são degradadas em suas unidades fundamentais: os polissacarídeos são degradados a hexoses e pentoses; os lipídeos em ácidos graxos, glicerol e outros componentes; e as proteínas em seus vinte aminoácidos primários. No segundo estágio, os produtos formados no primeiro estágio são reunidos e convertidos em um número menor de moléculas ainda mais simples. Assim, as hexoses, pentoses e glicerol são convertidos em piruvato, que depois é convertido em acetil-coenzima A; e os ácidos graxos e o esqueleto carbônico dos aminoácidos em grupos acetil, para formar acetil-CoA. E, por fim o grupo acetil do acetil-CoA é introduzido no ciclo do ácido cítrico, a via final comum, através da qual a maioria dos nutrientes fornecedores de energia são oxidados a dióxido de carbono. A água e a amônia são outros produtos finais do catabolismo. O anabolismo também ocorre em três estágios e inicia-se com moléculas precursoras pequenas e a partir delas ocorre a construção de grande variedade de macromoléculas ${ }^{7}$.

Antes de explicar a integração metabólica, se faz necessário o entendimento dos componentes energéticos da dieta e a bioenergética.

\subsection{Componentes energéticos da dieta}

O suprimento energético de um atleta é assegurado, fundamentalmente, pelos hidratos de carbono e pelas gorduras ou lipídios. As proteínas desempenham um papel plástico, apesar de, em algumas circunstâncias, também poderem assumir função energética.

\subsubsection{Carboidratos}

Os carboidratos constituem a fonte de energia mais abundante e prontamente disponível para a nutrição humana ${ }^{5}$.Os carboidratos importantes para dieta apresentam a fórmula geral $\left(\mathrm{CH}_{2} \mathrm{O}\right) \mathrm{n}$ e incluem os açúcares mais comumente consumidos, que podem subdivididos em monossacarídeos, como a glicose e a frutose, e dissacarídeos 
como sacarose, maltose e lactoses. Considerados carboidratos complexos, os polissacarídeos já incluem polímeros de glicose, amido e substâncias da parede celular não-digerível de plantas, como celulose, hemicelulose e pectinas, classificadas fibras dietéticas.

Os carboidratos da dieta são hidrolisados no estômago e intestino delgado a monossacarídeos, com um predomínio típico da glicose, que é o monossacarídeo mais abundante, assim como principal combustível da maioria dos organismos, por ser rica em energia e rapidamente mobilizada dos estoques de glicogênio quando ocorrem demandas súbitas de energia, já que o glicogênio é a principal forma de depósito de carboidratos em animais.

O reservatório corporal de carboidratos no corpo é muito pequeno e corresponde apenas a 1- 2\% da reserva total de energia, cuja principal forma de depósito é o próprio glicogênio hepático (80-90g) e muscular (300-400g). Por outro lado, a maior fonte potencial de combustível é o triglicerídeo hepático armazenado predominantemente mente no tecido adiposo e correspondente a $80 \%$ das reservas de substratos ${ }^{5}$.

Para os atletas, os carboidratos podem constituir o substrato energético mais importante para esforços de resistência e também o de primeira escolha para alguns esforços de intensidade elevada ${ }^{12}$.

Devido a ausência da enzima glicose-6-fosfatase no músculo, o glicogênio depositado no músculo constitui uma fonte prontamente disponível de glicose apenas nesse tecido, não podendo ser utilizada na corrente sanguínea. Ao contrário, no fígado a presença desta enzima permite que os hepatócitos desempenhem um papel predominante na mobilização do glicogênio armazenado para a manutenção do nível de glicose sanguínea, particularmente no estado pós-absortivo. A homeostase da glicose sanguínea é alcançada durante o jejum pela liberação hepática da glicose na mesma taxa de utilização pelos tecidos ${ }^{10}$.

O suprimento contínuo de glicose é importante pois serve como substrato primário para os sistema neurológico e eritrócitos.

\subsubsection{Lipídios}


Os lipídios formam um grupo heterogêneo de substâncias que inclui ácidos graxos livres (AGL) e substâncias encontradas naturalmente em associação química com eles. Os principais lipídios encontrados em seres humanos são AGL triglicerídeos, esteróides, fosfolipídios, prostaglandinas, vitaminas lipossolúveis, provitaminas e lipoproteínas.

Os lipídios mais abundantes são as gorduras ou triacilgliceróis, que são os principais combustíveis da maioria dos organismos. No entanto, são os lipídios polares os principais componentes das membranas celulares, onde ocorrem as reações metabólicas. As membranas não envolvem as células apenas, elas contêm muitas enzimas e sistemas de transporte importantes. Além disso, na superfície externa das membranas celulares estão localizados muitos sítios receptores ou de reconhecimento, que podem reconhecer outras células, ligar certos hormônios e detectar outros tipos de sinais do meio ambiente externo. Muitas das propriedades das membranas celulares são reflexos do seu conteúdo de lipídio polar ${ }^{6}$.

Os lipídios mais simples e abundantes que contêm os ácidos graxos como unidades fundamentais são os triacilgliceróis ou triglicerídios. Os triglicerídios são os principais lipídios ingeridos e armazenados dentro do corpo, e constitui-se de três ácidos graxos livres combinados com o glicerol. A digestão de triglicerídios, colesterol e fosfolipídios têm início no intestino delgado e termina com a entrada dos quilomícrons para o duto torácico, enquanto pequenas quantidades de AGL também são absorvidas diretamente pelo fígado através da circulação porta ${ }^{5}$.

Os triglicerídios atuam principalmente como lipídios de reserva, muito melhor adaptados do que o glicogênio para servir como forma de armazenamento de energia. Eles não apenas podem ser melhor armazenados em grandes quantidades, como também produzem por grama mais do dobro de energia que os carboidratos produzem.

As células também possuem lipídios não-saponificáveis, isto é os lipídios que não possuem ácido graxo e portanto não conseguem formar sabões. O colesterol é o principal esterol nos tecidos animais. O colesterol e seus ésteres com ácidos graxos de 
cadeias longas são componentes importantes das lipoproteínas plasmáticas e da membrana celular externa ${ }^{6}$.

Alguns lipídios estão associados com proteínas específicas formando lipoproteínas, muito importantes por possuírem a solubilidade das proteínas que garante a principal forma de transporte sanguíneo de lipídios.

As lipoproteínas plasmáticas transportam os produtos de síntese endógena e os lipídios exógenos ingeridos pela dieta, e podem ser classificadas de acordo com suas densidades em classes:

- $\quad$ Quilomícrons: triglicerídio exógeno primário.

- $\quad$ Lipoproteína de Densidade Muito Baixa (VLDL): triglicerídios primariamente endógenos.

- $\quad$ Lipoproteína de Densidade Baixa (LDL): aproximadamente $50 \%$ do transporte do colesterol, com mais colesterol e triglicerídios e menos proteína.

- $\quad$ Lipoproteína de Densidade Alta (HDL): normalmente transporta $20-25 \%$ do colesterol total do plasma e contém relativamente mais proteína e menos colesterol e triglicerídeos. ${ }^{3}$

\begin{abstract}
Como o organismo tem grandes estoques de energia na forma de lipídios, a suplementação com esse nutriente visando a performance atlética não é necessária, nem recomendada, pelos prejuízos à saúde que pode trazer se considerar o risco de doenças cardiovasculares associado. O que interessa para o praticante de atividade física é a mobilização destes lipídios do tecido adiposo e a adaptação a uma melhor oxidação periférica de lipídios para o fornecimento de ácidos graxos essenciais e vitaminas lipossolúveis importantes para a manutenção certas funções do organismo.
\end{abstract}

Os lipídios são a principal fonte de energia para os músculos em descanso e durante o exercício de baixa intensidade que exige menor velocidade metabólica na produção de ATPs em longa duração. A presença de AGL como combustível para a fibra muscular inibe a PFK e para a via glicolítica, preservando glicogênio e diminuindo a fadiga, além de preservar as proteínas para suas funções estruturais.

O metabolismo de lipídios e lipoproteínas é regulado por uma série de variáveis fisiológicas que podem afetar sua síntese e catabolismo. Essas variáveis incluem o 
envelhecimento, a genética, os hormônios, a composição da dieta, a ingestão calórica, o consumo de álcool, o tabagismo, medicações, composição corpórea e exercício.

Os lipídios mais utilizados no exercício são: os TGL do tecido adiposo, na forma de lipoproteínas, os TGL dos alimentos na forma de quilomícrons e os pequenos depósitos de TGL intramusculares.

\subsubsection{Proteínas}

As proteínas são as macromoléculas constituídas de cadeias de aminoácidos, unidos covalentemente em seqüências características, através de ligações peptídicas que conferem a cada uma propriedades e atividades muito diferentes entre si.

Todos os vinte aminoácidos encontrados em proteínas têm em comum um grupo carboxila e um grupo amino, ligados ao mesmo átomo de carbono, que diferem um do outro por suas cadeias laterais, ou grupos $\mathrm{R}$, as quais variam em estrutura, tamanho, carga elétrica e solubilidade em água. Os vinte aminoácidos de proteínas são freqüentemente referidos como aminoácidos padrão, primários ou normais, para distingui-los de outros tipos de aminoácidos, presente em organismos vivos, mas não em proteínas ${ }^{6}$.

Dos diferentes aminoácidos, nove não são adequadamente sintetizados no organismo para satisfazer as necessidades metabólicas e precisam ser obtidos através dos alimentos, sendo classificados em essenciais. Os demais aminoácidos produzidos no corpo são chamados não-essenciais, apesar de igualmente importantes para a estrutura da proteína. Assim sendo, uma proteína é considerada completa ou de alta qualidade quando contém todos os aminoácidos essenciais, tanto em quantidade quanto em proporções adequadas para promoção do crescimento normal. Esses aminoácidos são treonina, triptofano, histidina, lisina, leucina, isoleucina, metionina, valina e fenilalanina. Os demais aminoácidos não essenciais são igualmente importantes para a estrutura da proteína; entretanto, se as quantidades necessárias de 
aminoácidos dispensáveis não estiverem presentes no momento da síntese da proteína, eles poderão ser sintetizados a partir de aminoácidos essenciais ${ }^{9}$.

As proteínas são os instrumentos através dos quais é expressa a informação genética. Assim como existem milhares de genes no núcleo celular, cada um especificando uma caraterística distintiva do organismo, existem, correspondentemente, milhares de diferentes espécies de proteínas na célula, cada uma executando uma função específica determinada por seu gene. As proteínas, dessa forma, não são apenas as macromoléculas mais abundantes, mas também são extremamente versáteis em suas funções.

O aporte protéico ótimo para o desportista situa-se entre $12-15 \%$ do suprimento energético. No entanto, determinadas formas de prática desportiva podem aumentar estas necessidades, nomeadamente quando é necessário incrementar a síntese de proteínas musculares. O papel mais importante da suplementação protéica prende-se a aspectos qualitativos, atendendo à função desempenhada na constituição e reparação dos tecidos e síntese de enzimas ${ }^{12}$.

Pesquisas demonstram que atletas envolvidos em esportes recreativos ou ocasionais provavelmente não apresentam mudanças em seu metabolismo protéico ou requerimento de proteína, sendo satisfatórias as recomendações de proteína da população geral. À medida que o exercício aumenta em intensidade e duração, devem ser feitos ajustes significativos nas quantidades de proteínas ingeridas.

O objetivo do treinamento de força e ganho de massa é alcançar um balanço nitrogenado altamente positivo, cuja retenção de nitrogênio pode ser devido a uma diminuição na taxa de quebra da proteína ou síntese aumentada, ou ambos e irá requerer um consumo protéico aumentado ${ }^{10}$. 


\section{BIOENERGÉTICA}

O principal propósito das respostas fisiológicas ao exercício físico é o de prover energia para o desempenho durante a atividade física. Particularmente quando aplicada ao mundo biológico, o interesse na energia é direcionado para transformação da energia química em energia mecânica, que se manifesta no movimento humano ${ }^{3}$.

O fato de um indivíduo manter atividade muscular por algum tempo depende basicamente de sua capacidade em extrair energia dos nutrientes, obtidos a partir dos alimentos ingeridos na forma de carboidratos, gordura e proteínas, e transferi-las para os músculos ativos. Entretanto, a energia contida nos nutrientes, não pode ser diretamente transferida para o tecido muscular, mas é produzida mediante a ação de processos biológicos extremamente complexos e armazenada por intermédio de compostos fosfatados, dos quais o trifosfato de adenosina - ATP - é o principal representante.

Dessa maneira, a quebra do ATP em ADP e fosfato deverá ser caracterizada como a única fonte imediata de energia para o desenvolvimento da atividade física, porque produz energia necessária para que os filamentos de actina e miosiona dos músculos deslizem um ao longo do outro, provocando a contração muscular ${ }^{13}$.

Com a realização de sucessivas contrações musculares, na tentativa de oferecer continuidade ao desenvolvimento da atividade física, existe necessidade de que ocorra uma nova síntese constante das moléculas de ATP, tão rapidamente quanto estas são desintegradas. Logo, considerando que as quantidades de ATPs estocadas no tecido muscular são bastante limitadas para que o trabalho muscular possa ter prosseguimento, o organismo apresenta várias formas de reconstituição do ATP, com base em diferentes substratos energéticos. Neste particular, o tipo de substrato energético utilizado e a via metabólica com que o ATP é reconnstituído dependem fundamentalmente da intensidade e da duração dos esforços físicos ${ }^{13}$. 
Três vias metabólicas principais proporcionam energia para o desempenho de um exercício físico: a via anaeróbica alática (ATP - fosfocreatina), a via anaeróbica lática (glicose) e o metabolismo oxidativo (via aeróbica). A via mais importante para o exercício de longa duração é o metabolismo oxidativo, porque utiliza o oxigênio como combustível

O consumo máximo de oxigênio ( VO2 máx ) depende de vários processos essenciais, como ventilação pulmonar, trocas gasosas, débito cardíaco e utilização do oxigênio pelo músculo esquelético, e pode ser alterado por diversas condições.

De forma geral, para efeito de produção de energia, os esforços físicos deverão ser classificados em duas categorias: (a) aqueles considerados de elevada intensidade, porém de curta duração (anaeróbico); e (b) aqueles de baixa intensidade e longa duração (aeróbico) ${ }^{13}$.

\subsection{Atividades Aeróbicas X Atividades Anaeróbicas}

Nos esforços de alta intensidade, ou anaeróbicos, em que é necessária a produção de um número de moléculas de ATPs relativamente alto num espaço de tempo bastante curto, as moléculas de ATP necessárias à manutenção do trabalho muscular são sintetizadas, inicialmente, por intermédio de outro composto fosfórico de alta energia denominado fosfato de creatina - PC. Por esse sistema energético, considerando que o PC apresenta energia livre de hidrólise mais alta que ATP, quando a ligação entre as moléculas de creatina e de fosfato é desfeita, seu fosfato é unido ao ADP, formando os ATPs necessários à contração muscular ${ }^{3}$.

Assim como no desdobramento do ATP em ADP e Pi, essas reações também são reversíveis, fazendo com que, creatina e fosfato se unam novamente na disponibilidade energética.

Apesar de existir de 3 a 5 vezes mais do que ATP, o fosfato de creatina também é armazenado em pequenas quantidades. Portanto, o fornecimento de energia, por 
essa via metabólica também é muito reduzido e atende aos esforços físicos de elevada intensidade, por não mais do que 8-10 segundos. A menos que se diminua a intensidade, para que o esforço físico possa ser mantido por mais algum tempo, uma segunda via metabólica é acionada com o intuito de produzir os ATPs necessários à continuidade das contrações musculares, a Glicólise.

A glicólise anaeróbica consiste na degradação do glicogênio ou da glicose para piruvato ou lactato mediante o envolvimento de uma série de passagens enzimáticas catalizadoras, que resulta na produção das moléculas de $\mathrm{ATP}^{3}$.

A ativação do metabolismo anaeróbico ou não-oxidativo e aeróbico ou oxidativo dependerá basicamente da velocidade exigida na produção da energia para o trabalho muscular. Se os esforços físicos forem de elevada intensidade, elevando a velocidade metabólica na produção de energia, deverá ser ativado o sistema anaeróbico, pois o fornecimento de oxigênio para as reações torna-se insuficiente. Contudo, se os esforços físicos forem de baixa a moderada intensidade, exigindo, por sua vez, menor velocidade metabólica na produção de ATPs, deverá ser ativado predominantemente o sistema aeróbico, tendo em vista que as reações metabólicas realizadas na presença do oxigênio são suficientes para produzir o ATP necessário ${ }^{3}$.

Quando a intensidade dos esforços físicos diminui, permite que o sistema de produção de energia venha a sintetizar os ATPs necessários à contração muscular a partir do metabolismo aeróbico. Neste aspecto, quanto mais tempo durarem os esforços físicos, maior deverá ser a participação das reações oxidativas nas exigências energéticas, ao mesmo tempo em que a produção de energia por meio das vias anaeróbicas diminuirá gradativamente.

Ao contrário do metabolismo anaeróbico, em que apenas o carboidrato é utilizado como substrato energético, o metabolismo aeróbico pode usar, além do carboidrato, os lipídios e, em casos de duração extrema, as proteínas, como substratos para a produção de ATPs. Além do mais, o metabolismo aeróbico é o mais eficiente do ponto de vista de produção energética, pois além de sintetizar ATPs sem acúmulo de 
ácido lático, por essa via, forma-se muito mais ATPs comparativamente com a via anaeróbica ${ }^{3}$.

Quanto à duração, com o passar do tempo sob esforço físico, os estoques do glicogênio muscular diminuem e concomitantemente as quantidades de ácidos graxos livres na corrente sanguínea se elevam. Assim, a participação dos substratos na produção de energia tende a se inverter, diminuindo a participação do metabolismo de carboidratos e acentuando a participação do metabolismo do metabolismo de gorduras. Com relação à intensidade, em esforços físicos de baixa a moderada intensidade as necessidades energéticas são atendidas prioritariamente pelos ácidos graxos livres, no entanto, ao elevar o nível de intensidade, a glicose passa a ser a principal fonte de energia $^{13}$.

\title{
3.1.1 Sistema ATP-CP
}

\begin{abstract}
Apesar de o ATP servir como corrente de energia para todas as células, sua quantidade é limitada, de forma que apenas 85g de ATP são armazenados de uma vez no organismo. Parte da energia para regeneração do ATP é fornecida direta e rapidamente pela divisão anaeróbica de uma molécula de fosfato proveniente de outro composto rico em energia denominado fosfato de creatina ou CP, em parte, semelhante ao ATP pela grande quantidade de energia liberada pela divisão das moléculas que a compõem.
\end{abstract}

Assim como se aplica ao ATP, as reações entre creatina e fosfato são reversíveis e podem ser reunidos novamente para formar $\mathrm{CP}$. Se a regeneração de ATP ocorre se suficiente energia for utilizada na reunião de uma molécula de ADP com outra de fosfato, a divisão de CP pode fornecer esta energia de forma quase instantânea e sem requerer oxigênio. Por esta razão o CP é considerado um reservatório de alto potencial energético.

Em quase todos os esportes, a capacidade do sistema de energia ATP-CP pode desempenhar um importante papel para o sucesso ou fracasso em algumas fases da performance, por proporcionar curtas mas intensas descargas de energia cruciais para o sucesso de algumas atividades. Futebol americano, tênis, esportes de pista e campo, golfe, voleibol e beisebol são exemplos dessas atividades ${ }^{2}$. 
A quantidade de ATP presente nos músculos é suficiente para manter uma potência muscular máxima por 5 a 6 segundos. Se considerarmos que temos 2 a 3 vezes mais fosfocreatina, em conjunto, pode ser uma proporcionada potência muscular máxima por 10 a 15 segundos muito importante para o atleta ${ }^{10}$.

\subsubsection{Glicólise Anaeróbia}

Quando uma molécula de glicose entra numa célula para ser utilizada como fonte de energia, ela imediatamente passa por uma série de reações químicas, denominadas como glicólise, que ainda recebem o termo de anaeróbias por não requerer oxigênio ${ }^{2}$. Como resultado da reação enzimática, a molécula original de carbono-6 de glicose é transformada em duas moléculas de carbono-3 de ácido pirúvico, no meio intracelular.

O piruvato formado como produto final da glicólise pode seguir diferentes vias catabólicas, dependendo do organismo considerado e das condições metabólicas em que se encontra. Uma delas é ser oxidado, formando o grupo acetil da acetil-coenzima A, que é oxidado pelo ciclo do ácido cítrico a $\mathrm{CO}_{2}$ e $\mathrm{H}_{2} \mathrm{O}$, com a intervenção do oxigênio molecular. Outra via possível ao piruvato é a sua redução a lactato quando o indivíduo precisa funcionar anaerobicamente, especialmente o músculo esquelético em contração vigorosa ${ }^{7}$.

A extração de energia utilizável durante as reações anaeróbicas da glicólise representa apenas $5 \%$ do número total de ATPs produzidos quando a molécula é decomposta totalmente até dióxido de carbono e água, durante as reações aeróbicas subsequentes. No entanto, a produção de ATP durante a glicólise é importante por fornecer uma rápida, ainda que limitada fonte de energia para a atividade muscular ${ }^{2}$. 


\subsubsection{Metabolismo Aeróbio}

Se há oxigênio suficiente, o ácido pirúvico penetra na mitocôndria das células musculares e reage com o oxigênio para formar mais moléculas de ATP e liberar energia, que é extraída quando o ácido pirúvico é descarboxilado em uma acila, que se une a coenzima A formando o Acetil CoA para dar início, primeira etapa da fase aeróbia denominada de ciclo de Krebs ou ciclo do Ácido cítrico.

No líquido intracelular, os átomos de hidrogênio são liberados à medida que as moléculas de glicose são degradadas em ácido pirúvico durante a glicólise e durante a subsequente transformação do ácido pirúvico em acetil CoA. Nas reações intramitocondriais os átomos de carbono e hidrogênio são retirados das moléculas de Acetil CoA, gerando assim 2 moléculas de ATP, 16 hidrogênios adicionais e a formação de 4 moléculas de dióxido de carbono no ciclo de Krebs ${ }^{2}$.

Nesse sistema, os átomos de hidrogênio são transformados em partículas eletricamente carregadas que passam através de uma cadeia de reações em funil carreados por portadores especiais de moléculas até alcançarem o "fim da linha", onde se combinam com o oxigênio para formar água, que caracteriza a fase crucial do metabolismo energético pois é durante a transferência de elétrons que há produção de energia para religar um $\mathrm{P}$ ao ADP para formar ATP.

Enquanto a rápida liberação anaeróbica de energia da molécula de glicídio, durante a glicólise, determina em grande escala a performance de um exercício máximo de curta duração, é a capacidade individual de regeneração de ATP que é fundamental para sustentar atividades físicas com duração acima de 2 minutos ${ }^{2}$. 


\subsection{Perfil Metabólico dos Principais Órgãos ${ }^{7}$}

Cérebro: A glicose é virtualmente o único combustível para o cérebro humano, exceto durante um jejum prolongado. Durante a inanição, os corpos cetônicos substituem parcialmente a glicose como combustível para o cérebro.

Músculo: Os principais combustíveis para o músculo são a glicose, os ácidos graxos e os corpos cetônicos. Ele difere do cérebro por ter uma grande reserva de glicogênio.

No músculo esquelético em contração ativa, a velocidade da glicólise excede aquela do ciclo do ácido cítrico. Grande parte do piruvato formada nessas condições é reduzida a lactato, que flui para o fígado, onde é convertido a glicose.

Já no músculo em repouso, os ácidos graxos são os principais combustíveis.

Tecido Adiposo: Os triglicerídios armazenados no tecido adiposo constituem um imenso reservatório de combustível metabólico. No ser humano, o fígado é o local principal de síntese de ácidos graxos, enquanto a principal tarefa biossintética do tecido adiposo é ativar esses ácidos graxos e transferir os derivados CoA resultantes ao glicerol.

As células adiposas precisam de glicose para a síntese de triglicerídios.

Fígado: As atividades metabólicas do fígado são essenciais para o provimento de material energético para o cérebro, músculo e outros órgãos periféricos. O fígado pode captar glicose em grandes quantidades e convertê-la em glicogênio.

O fígado também desempenha um papel central na regulação do metabolismo lipídico. 


\section{CREATINA}

A creatina foi primeiramente identificada por Chevreul em 1835 em um pedaço de carne e desde o início do século já era apontada a sua importância para contração muscular. A creatina é uma amina nitrogenada formada no fígado, rins e pâncreas, a partir dos aminoácidos arginina, glicina, e metionina.Em geral, pode ser encontrada, primariamente no músculo esquelético (90-95\%), estando o restante presente no coração, na musculatura lisa, no cérebro e no testículos.

Para a população em geral, a creatina foi divulgada em 1992, quando nos Jogos Olímpicos de Barcelona, muitos atletas vencedores declararam ter ingerido este produto como suplemento dietético. Num artigo da "Peak Performance" (1993), no qual foi feita uma revisão sobre o tema, concluiu-se que a creatina influenciava, positivamente a performance dos atletas. Por se acreditar que o aumento de creatina no músculo permitiria um estoque maior de fosfocreatina, e conseqüentemente de energia extra na forma de trifosfato de adenosina, a ingestão de creatina tornou-se comum entre os atletas profissionais e se espalhou entre atletas amadores, inclusive em crianças.

\subsection{Mecanismo de Ação da Creatina}

A reação creatina fosfato $(\mathrm{CP})+\mathrm{ADP}+\mathrm{H}^{+} \leftrightarrow$ creatina + ATP , promovida pela enzima creatina quinase (CPK) é imprescindível para a contração muscular, uma vez que permite a imediata reposição de ATP no citosol da célula (Figura 1). 


\section{Figura 1: Reação da creatina quinase.}
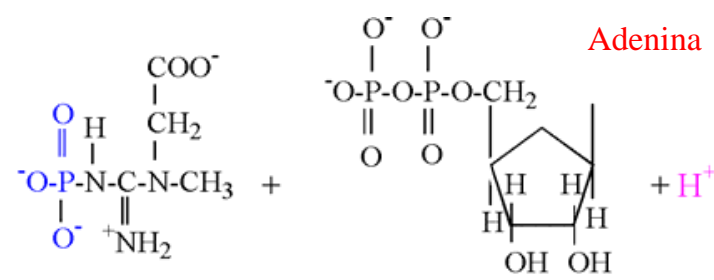

Creatina fosfato

ADP
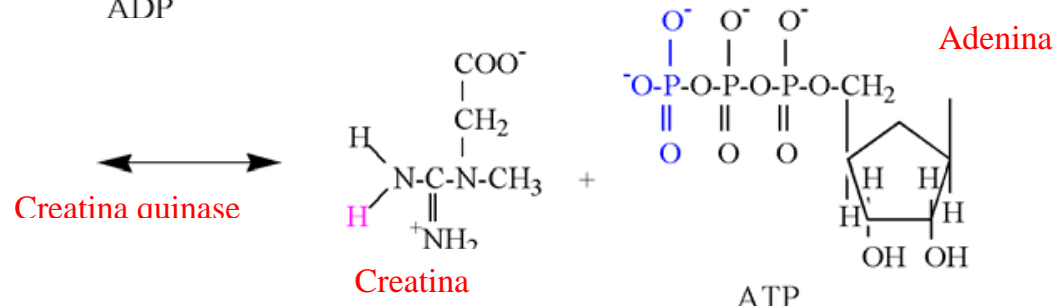

ATP

Além de repor as necessidades de ATP durante o exercício físico, esta reação promove, pela presença da molécula creatina fosfato, a transferência de fosfatos da mitocôndria para o citosol, denominada de "creatine phosphate shuttle", que caracteriza-se pela difusão da creatina por três locais: área de utilização (miosina), área de transição e área de fosforilação da creatina (Karlsson, 1971; Kent-Braun et al., 1993). A reação envolve a transferência de um grupo fosfato da molécula CP para o ADP e formação de ATP, cuja bioquímica indica que um próton do meio é consumido para cada grupo fosfato transferido da CP para ATP, o qual é utilizado para a recomposição do amino terminal da creatina ${ }^{14}$.

Este processo acontece após a degradação dos compostos sintetizados durante a digestão de alimentos ingeridos, tal como os carboidratos. Num período muito curto de tempo após o início de um exercício intenso, as reservas de ATP nos músculos em atividade esgotam-se. Para que a contração muscular possa continuar, ou seja, para que o exercício possa ser mantido, os níveis de ATP têm de ser repostos, o que ocorre inicialmente através da transferência de um grupo fosfato da fosfocreatina que é formada quando a taxa de consumo de ATP requerida é menor do que a produzida pela energia libertada pelas reações catabólicas envolvidas na degradação dos alimentos². 
A formação de ATP é a estratégia básica do metabolismo. O ATP ou adenosina trifosfato, é um nucleotídeo constituído de uma adenina, uma ribose e uma unidade trifosfato e gerado pela oxidação de moléculas alimentares, tais como glicose, ácidos graxos e aminoácidos,constituindo assim uma unidade básica de energia para todas as células do organismo e muito importante para as células e para a contração muscular ${ }^{15}$. A contração muscular necessita da quebra (hidrólise) do ATP em ADP e Pi, cuja enzima miosina ATPase é responsável por esta reação (Figura 2). O ATP hidrolisado é o estímulo primário para o aumento do catabolismo e, portanto de geração de mais energia.

\section{Figura 2: Hidrólise do ATP}

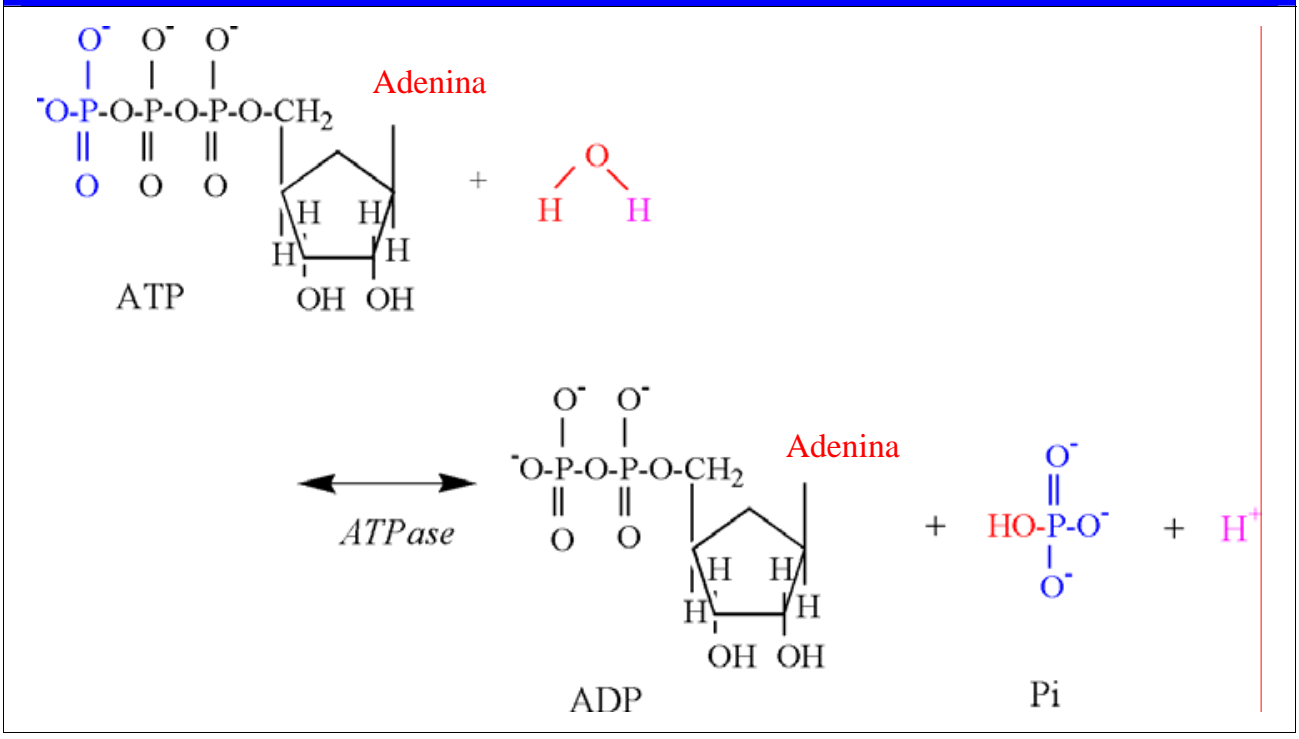

Em todas as atividades físicas há quebra de ATP em ADP ou adenosinadifosfato, e é nessa quebra que ha liberação de energia. Apesar das principais fontes para a do ATP serem gorduras e carboidratos, a obtenção de energia a partir destas fontes requer um tempo para reativação de vias metabólicas. Neste intervalo, a regeneração de ATP é totalmente dependente da fosfocreatina. 


\section{Distribuição da Creatina}

Acredita-se que o músculo humano apresente um limite máximo de acúmulo de creatina entre 150 e 160 mmol/kg, sendo que o "turnover" diário da creatina em um homem de $70 \mathrm{~kg}$ é de aproximadamente $120-125 \mathrm{mmol} / \mathrm{kg}$ e sua concentração plasmática apresenta-se entre 40 e $100 \mathrm{mmol} / \mathrm{litro}^{31}$.

De acordo com Mujika et al (1997), a concentrações de creatina livre e creatina fosforilada estão diretamente relacionada com os tipos de fibras musculares, observando-se maior concentrações nas fibras de contração rápida (tipos Ila e Illb) em relação às fibras de contração lenta (tipo I). As contrações e relaxamentos das fibras musculares, que caracterizam o exercício físico só são possíveis pela energia libertada durante o processo de desfosforilação da adenosina trifosfato. Cerca de $98 \%$ da quantidade total de creatina no organismo humano está contido nos músculos com fibras do tipo II, fibras de rápida contração que geram maior força. Por outro lado, as fibras do tipo I, parecem regenerar o fosfato de creatina mais rapidamente quando comparadas com as do tipo II, apesar de serem fibras de contração lenta, que mantém normalmente o metabolismo aeróbio e, nesta fase, tem uma capacidade de gerar ATP muito maior do que as fibras do tipo $\mathrm{I}^{20}$.

Uma vez que o músculo não sintetiza creatina, a concentração intracelular é dependente da captação deste componente a partir do plasma. Estudos demonstram que a captação de creatina nos tecidos também possa ser mediada pela insulina, assim como a ingestão de carboidrato com creatina facilita a captação de creatina em comparação à ingestão isolada desse nutriente, pela possibilidade a captação aumentada ocorrer em função da liberação de insulina estimulada pela glicose.

O conteúdo de creatina muscular é bastante estável. Cerca de $60-70 \%$ do total de creatina muscular apresenta-se sob a forma de creatina fosfato, que é incapaz de passar por membranas, mantendo-se, dessa forma, na célula ${ }^{22}$. 


\subsection{Creatina como Suplemento}

A princípio a suplementação de creatina tinha como principal enfoque a necessidade de se aumentar a produção de energia através do sistema ATP-CP. Atualmente, sabe-se que a ingestão de creatina pode aumentar significativamente a quantidade de trabalho a ser produzida durante exercícios repetitivos de esforço máximo. Acredita-se que os efeitos ergogênicos provocados pela suplementação de creatina sejam atribuídos ao aumento do conteúdo total de creatina intramuscular , acelerando a ressíntese de fosfocreatina no intervalo dos exercícios.

Apesar de a creatina apenas ter passado a ser conhecida há pouco tempo no meio desportivo, já se fazem estudos quanto ao seu uso como suplemento desde meados dos anos 20 (1926, mais precisamente). Os mecanismos que fazem com que a creatina prolongue um determinado exercício parecem ir além da sua habilidade de regenerar ATP. É sabido também que o fosfato de creatina é capaz de neutralizar certos ácidos produzidos durante os exercícios, que baixam o $\mathrm{pH}$ do sangue e que contribuem desta forma para a fadiga muscular.

Outra forma da creatina inibir relativamente o cansaço muscular é através da ativação de um processo metabólico produtor de ATP que envolve glicose. Estudos laboratoriais revelam que a glicose é estimulada por um decréscimo dos níveis de creatina, assim que o fosfato de creatina começa a regenerar os níveis de ATP ${ }^{15}$.

\footnotetext{
Quanto ao ganho de massa corporal relacionado com a creatina, até agora ninguém tem realmente a certeza de qual o causador. Num artigo escrito acerca deste tópico, na revista americana "Journal of Strenght and Conditioning Research", os autores apontam que o fato da retenção de água pode não ser o único responsável por este aumento, mas também o fato de que é possível que a creatina afete a síntese protéica de uma forma positiva, o que significa músculos maiores e mais fortes ${ }^{15}$.
}

Existem provas de que a creatina estimula a produção de proteínas musculares. Além do mais, não se depara com nenhum ganho extra de gordura corporal, o que é 


\section{bom do ponto de vista atlético. Apesar disso, deve-se referir que o mecanismo (se é que existe) pelo qual a creatina afeta o metabolismo protéico ainda está atualmente a ser investigado.}

Várias pesquisas concluem que a suplementação de creatina monohidratada aumenta os níveis de creatina e creatina fosfato musculares, melhorando a performance, principalmente em atividades de alta intensidade e curta duração (em torno de 10 a 20 de segundos). Destaca-se ainda o aumento da força gerado pela utilização de creatina na forma de suplemento devido a:
- Aumento da massa muscular devido ao aumento dos substratos energéticos intramusculares como fosfocreatina, glicogênio e água (volumização celular)

- O ambiente super-hidratado propicia a síntese protéica

- Prolonga esforços de alta intensidade

- Acelera a recuperação, permitindo maior freqüência de treinamento

- Tamponamento do lactato, absorvendo íons de $\mathrm{H}+$, aumentando assim a resistência à fadiga. Tal situação ainda é hipotética (motivo de discussão) ${ }^{22}$

\subsubsection{Efeitos Ergogênicos da Suplementação}

A creatina tem uma ocorrência natural no corpo humano, sendo a principal fonte de energia do músculo em estímulos de alta intensidade. Pesquisas realizadas nos últimos anos descobriram que o corpo humano é capaz de armazenar mais creatina do que normalmente consumimos numa dieta normal, se considerar que indivíduos normais produzem cerca de dois gramas de creatina por dia.

Inúmeros estudos revelam a possibilidade de um aumento da concentração muscular em creatina se repercutir em benefícios no desempenho de esforços rápidos, repetidos e de elevada intensidade, como conseqüência do aumento de creatina fosfato. Além disso, outro proposto efeito da suplementação de creatina é o aumento a massa corporal, particularmente da massa muscular; possivelmente por atrair água para a célula como agente osmoticamente ativo, promovendo maior retenção de água dentro da célula muscular, ou ainda, por estimular a síntese protéica ou diminuir a degradação de proteínas através do aumento na hidratação celular e/ou creatina fosfato, como sugerem algumas pesquisas.

Entretanto, ganhos na massa corporal podem ergogênicos para alguns atletas, como levantadores de peso, mas contraproducentes para outros, como corredores de distância, ou atletas envolvidos em esportes nos quais o corpo 
necessita ser movido o mais eficaz e rapidamente possível. Se os possíveis ganhos na produção de energia forem superados por um aumento na massa corporal, o desempenho pode não ser melhorado e até impedido ${ }^{27}$.

No geral, a suplementação de creatina a curto prazo pode contribuir para a massa corporal total aumentada, pelo menos em homens, ainda que grande parte desse aumento possa ser atribuído à retenção de água mais que à proteína contrátil aumentada, seja em indivíduos sedentários ou fisicamente ativos. Já a suplementação crônica de creatina ( 2-12 semanas ), combinada com o treinamento de força, pode aumentar a massa corporal magra, quanto em várias mensurações da massa isenta de gordura, sendo necessário no entanto, mais pesquisas que apóiem estas afirmativas.

Além disso, acredita-se que a suplementação de creatina também possa ser ergogênica por previnir a fadiga, ao elevar os níveis de ATP e fosfocreatina durante o exercício, e assim, reduzir a acidez muscular ao consumir H+ no processo de regeneração da molécula de creatina (Figura 1) e ATP, o que previniria o acúmulo de ácido láctico no músculo, efeito que ainda continua sem comprovação pela existência de resultados contraditórios ${ }^{16}$. 


\subsubsection{Efeitos Ergolíticos da Suplementação}

Ainda que a suplementação de creatina possa ser ergogênica para certos exercícios ou esforços esportivos, a literatura sugerem que ela também pode ser ergolítica, ou reduzir o desempenho, em outros tipos de eventos. Segundo Clark (1997), o aparente aumento no metabolismo anaeróbio causado pela suplementação de creatina pode produzir mais lactato e, portanto, tornar o atleta mais propenso à acidose láctica.

Um aumento de massa corporal induzido pela suplementação de creatina, especialmente não sendo massa muscular, também poderia ser prejudicial para o desempenho em esportes nos quais essa massa precisa ser deslocada, como corredores de longa distância, que teriam que gastar mais energia oxidativa para mover massa extra; diferentemente de velocistas ou maratonistas, em que aumentos na potência produzida poderia contrabalancear os efeitos potencialmente adversos de um aumento da massa corporal ${ }^{29}$.

Por outro lado, nem todos os indivíduos expostos a uma sobrecarga de creatina aumentam as concentrações musculares de creatina total e fosforilada, que sustenta o fato de haver diferenças individuais substanciais nas respostas à suplementação de creatina.

Quanto aos efeitos colaterais, não se tem ainda provas de que a suplementação de creatina possa causar algum dano; o que existe, na realidade, são pesquisas sobre os efeitos dessa suplementação sobre marcadores da condição clínica do indivíduo e possíveis riscos à saúde, que envolvem sua síntese endógena, a função renal, o efluxo enzimático muscular e hepático, a pressão arterial e perfil lipídico ${ }^{30}$.

Ainda que o consumo de creatina possa suprimir sua síntese endógena durante o período de suplementação, não há evidências de que tal supressão se torne crônica, após a sua interrupção; tal como pode ser observado aumento do efluxo de enzimas musculares e hepáticas durante o exercício intenso, como indicadores da intensidade do exercício ou estresse do treinamento, independente da suplementação de creatina, conforme 
achados de pesquisa. Uma vez que a creatina tem sido associada com o ganho de peso, ainda surgiram questionamentos a respeito de sua relação com a pressão arterial e perfil lipídico dos indivíduos, sem ter sido demonstrado efeito, apesar dos aumentos significativos no peso corporal total, na massa magra ou em ambos.

O que denota maior atenção é a função renal, cujo exercício intenso e a desidratação também podem servir para aumentar a excreção sérica e urinária da creatinina, usados normalmente como indicadores básicos da degradação tecidual e/ou estresse renal. De acordo com relatos, os níveis séricos e urinários de creatinina não são afetados ou aumentam ligeiramente após a suplementação de creatina. Para Harris e Poortmans et al (2000),o aumento dos mesmos refletem uma liberação e metabolismo aumentados de cretinina intramuscular, que ocorre em consequência do turnover protéico aumentado e/ou maior volume de treinamento em resposta a suplementação de creatina. Já outros atestam que a elevação na creatinina sérica e urinária após a suplementação de creatina pode ser indicativo de um maior estresse renal, o que corrobora para que a possibilidade dessa suplementação aumentar o estresse renal não ser completamente desconsidera danos poucos estudos de curto e longo prazo que avaliaram seus efeitos sobre a função renal.

Segundo Strauss (1998), o efeito colateral não comprovado mais reportado da suplementação de creatina é a maior incidência de desidratação, cãibras musculares ou intolerância ao calor em atletas que treinam intensamente em ambientes quentes e úmidos. Uma vez que a creatina pode permitir ao atleta treinar mais intensamente, isso pode o predispor à desidratação se levar em consideração a retenção hídrica durante as primeiras fases da suplementação. Por outro lado, um suposto aumento na água intracelular poderia perturbar o balanço eletrolítico intracelular normal, induzindo as cãibras musculares. No entanto, ainda é preciso que se realizem pesquisas bem controladas para avaliar tais efeitos.

\section{Como efeitos colaterais de curto prazo, alguns podem sentir desconforto estomacal e diarréia. Nestes casos deve-se reduzir a dose ou comprar a creatina micronizada.}

A literatura ainda faz menção a um possível efeito carcinogênico da creatina quando aquecida ou quando ingerida com alimentos que contenham nitrato ou nitrito (carne preparada em salmoura, espinafre, saladas). Por esse motivo, o suplemento somente deve ser usado quando prescrito por um médico ou nutricionista.

\subsubsection{Prática da Suplementação de Creatina}


Com base no mecanismo de ação da creatina, a suplementação de creatina pode beneficiar o desempenho em uma variedade de exercícios e esforços esportivos, tais como sprint de intensidade muito elevada, como em corridas de 100 e 200m, pela disponibilidade aumentada de creatina fosfato; atividades repetitivas de alta intensidade com pausas freqüentes, como o tênis ou hóquei no gelo, pela ressíntese aumentada de CP; tarefas anaeróbias mais prolongadas, tais como corridas de 400 e $800 \mathrm{~m}$, pela suposta acidez muscular reduzida; e ainda, esportes como levantamento de peso e futebol americano, em função do aumento de massa corporal e ganhos de força e potência associados.

De acordo com a literatura, pode-se considerar que a creatina se aplica melhor em :

- Atletas envolvidos em provas em que as qualidades físicas, força máxima e força explosiva são importantes;

- Body Builders (culturistas), dado que esta não só lhes permite atingir cargas mais importantes, como também maximizar a formação de tecido muscular;

- Atletas envolvidos em desportos que implicam esforços de potência, prolongados e intensos como: Futebol, Rugby, Handebol, Basquetebol e Remo ${ }^{16}$.

Com relação as doses recomendadas, a indicação mais comum de que a administração de creatina deva ser feita em duas fases: fase de saturação e de manutenção. Na fase de saturação da célula, vêm obtendo-se resultados com 20-25 gramas por dia (dividido entre 3 a 5 vezes ao dia) durante um período de 5 dias (fase de carga) para um melhor rendimento, após o qual costuma-se usar 5 a 10 gramas diárias em duas doses de manutenção, que depende do volume corporal. Estudos recentes mostram que o maior consumo de creatina pelo tecidos ocorre nos primeiros dias de suplementação e, após o carregamento muscular de creatina, os seus níveis tendem a manter-se até um período de 1 mês.

Mesmo sendo o nível de creatina depositável nos músculos limitado, a dose de manutenção é altamente recomendável, uma vez que podem manter ostensivamente os níveis totais de creatina estabilizados após as doses 
iniciais, efeito que é amplificado em indivíduos que apresentam deficiência na concentração de creatina como vegetarianos, por exemplo.

A creatina está disponível no mercado de diversas formas e inúmeras marcas. Os exemplos citados abaixo são referentes a alguns tipos de creatina existentes:

- Creatina em pó micronizada : É uma creatina micro ultra filtrada, beneficiando o suplemento de creatina para uma absorção maior e mais rápida pelo sistema sanguíneo e finalmente chegar ao músculo, aumentando o nível energético necessário para uma melhor performance anaeróbica. Estudos dizem que é 10 vezes mais assimilável pelo sistema digestivo que a creatina comum, porque se dissolve instantaneamente na água, tendo seu armazenamento energético nas células muito mais rápido e melhorando na produção de ATP.

- Creatina em Drágea: Geralmente contém de 700 a 850 mg de Monohidrato de Creatina em cada drágea. Não é micronizada, nem apresenta aditivos em sua composição, sendo recomendada somente para aqueles que têm dificuldade de tomar a creatina em pó.

- Creatina em pó: É a creatina monohidratada pura, tendo sido a primeira forma de creatina lançada no mercado há dez anos.

- Creatina com aditivos: Geralmente esse tipo de creatina tem glutamina, taurina e carboidratos na fórmula, além de outros aminoácidos.

- Creatina efervescente: Promete uma rápida absorção e ação imediata no organismo.

- Creatina Líquida: Acredita-se que a absorção é maior e evita problemas intestinais.

- Creatina em forma de chiclete: Da mesma forma que a creatina em cápsulas, sua vantagem é a praticidade. 



\section{RECURSOS DA ALIMENTAÇÃO}

Uma dieta ótima pode ser definida como aquela em que o suprimento de nutrientes requerido é adequado à manutenção, crescimento e reparo dos tecidos, sendo consenso geral que homens e mulheres treinados e ativos não necessitam de acréscimo de nutrientes além do obtido através de uma dieta bem balanceada. À medida que aumenta significativamente o dispêndio energético, a demanda alimentar também aumenta proporcionalmente para manutenção do peso corporal ${ }^{3}$.

Os alimentos ricos em proteínas eram o esteio das dietas de atletas, que costumavam ingerir excessivamente carne bovina, ovos, atum, galinha e outros alimentos ricos em proteínas. No entanto, a melhor dieta de esporte contém adequada, mas não excessiva, proteína para construir o tecido muscular, sendo queimada como fonte de energia ou é armazenada como glicogênio ou gordura qualquer proteína em excesso.

Muitas evidências sugerem que não traz dano à saúde sustentar-se principalmente de glicídios, desde que também estejam presentes na dieta os aminoácidos essenciais, os minerais e as vitaminas.

Com relação a creatina, as principais fontes na dieta são o peixe e a carne vermelha, com aproximadamente $3-5 \mathrm{~g}$ do nutriente no peixe, como atum, salmão e bacalhau, e na carne, como bovina e suína, não cozidos. O arenque contém cerca de 6$10 \mathrm{~g}$ de creatina por quilograma. Entretanto, o processo de cozimento pode degradar parte da creatina encontrada nos alimentos, diminuindo assim a quantidade de creatina disponível a partir de fontes da dieta, dependendo do modo de preparo do alimento ${ }^{30}$.

De modo geral, a ingestão de creatina na dieta pode variar consideravelmente. Para vegetarianos radicais, que não consomem nenhum produto de origem animal, a ingestão diária de creatina seria zero e a síntese endógena, única fonte desse nutriente. No caso de indíviduos sem restrição dietética, cuja ingestão protéica fica entre 1 e $2 \mathrm{~g} / \mathrm{kg}$ de peso corporal por dia, obtem entre 0,25 e 1g/dia de creatina a partir da dieta. Ainda que seja possível aumentar a ingestão diária de creatina pelo consumo de alimentos ricos nesse nutriente, é difícil obter mais que 3-4 g/dia por meio de alimentares, conforme demonstrado na tabela a seguir:

\begin{tabular}{lc}
\hline Alimento & Quantidade de Creatina $(\mathrm{g} / \mathrm{kg})$ \\
\hline Camarão & vestígios \\
Bacalhau & 3 \\
Atum & 4 \\
Salmão & 4,5 \\
\hline
\end{tabular}




\begin{tabular}{lc}
\hline Arenque & $6,5-10$ \\
Carne de vaca & 4,5 \\
Carne de porco & 5 \\
Leite & 0,1 \\
\hline
\end{tabular}

\section{CONCLUSÃO}

A descoberta da creatina ocorreu em 1835, mas apenas em 1992 foi iniciada a prática de seu uso na forma de suplemento, amplamente difundida nos últimos dez anos. Apesar dos efeitos da ingestão de creatina não serem completamente conhecidos, não existem dados na literatura que sugiram risco significativo à saúde se ingerida nas doses recomendadas. Contudo, indivíduos que considerarem a possibilidade de utilizar a suplementação de creatina deve estar atentos aos possíveis riscos de doses excessivas procurando orientação de profissionais de saúde treinados, que levem em consideração o tipo de atividade física a ser praticada, dose e duração da suplementação.

Apesar de eficácia da suplementação com creatina continuar em discussão, os atuais dados de pesquisas científicas conferem a creatina grande credibilidade no que se refere a melhoria da performance atlética, tanto em 
homens quanto em mulheres, sendo apontada pela maioria deles como um agente ergogênico que melhora o

desempenho em esportes repetitivos de alta intensidade e curta duração (explosão e força).

Considerando o presente trabalho, conclui-se que atletas de elite podem ser efetivamente beneficiados com a suplementação de creatina uma vez que o potencial de risco fica minimizado pelo acompanhamento de profissionais técnicos e treinamento. Vale ressaltar no entanto, que o desempenho físico com saúde de qualquer individuo fisicamente ativo ou simplesmente engajados em alguma forma de treinamento físico requer uma alimentação equilibrada e conciliada a atividade física, uma vez que a suplementação de creatina ainda demonstra muitas particularidades a serem estudadas e o assunto ainda requerer pesquisas bem monitoradas para avaliar seus efeitos.

\section{REFERÊNCIAS BIBLIOGRÁFICAS}

1. SETtINERI, Luiz Irineu Cibilis. A Alimentação do Atleta. Porto Alegre. Movimento/Instituto Nacional do Livro/MEC: Editora Movimento,1974.

2. KATCH, Frank I., MCARDLE, Willian D., ROCHA, Maurício Leal. Nutrição, Controle de Peso e Exercício. $3^{\mathrm{a}}$ ed. Rio de Janeiro: Editora Médica e Científica Ltda., 1990.

3. MCARDLE, W. D., KATCH, F.I. \& KATCH, V.L. Fisiologia do Exercício, Energia, Nutrição e Desempenho Humano. Guanabara Koogan, Rio de Janeiro, 1992.

4. CLARK, Nancy. Guia de Nutrição Desportiva: alimentação para uma vida ativa. $2^{\mathrm{a}}$ ed. Porto Alegre: Artmed, 1998.

5. WOLINSKY, Ira, HICKSON JR., James F. Nutrição no Exercício e no Esporte. $2^{\mathrm{a}}$ ed. São Paulo:Roca, 1996.

6. LEHNINGER, Albert L. Princípios de Bioquímica. $5^{\mathrm{a}}$ ed. São Paulo: Sarvier, 1998.

7. STRYER, Lubert. Bioquímica.3a ed. Rio de Janeiro:Guanabara Koogan, 1992. 
8. GUYTON, Arthur C. Fisiologia Humana e Mecanismos das Doenças. $5^{\mathrm{a}}$ ed. Rio de Janeiro:Guanabara Koogan, 1993

9. KRAUSE, M. V., MAHAN, L. K. Alimentos, Nutrição e Dietoterapia. $7^{\mathrm{a}}$ ed. São Paulo: Roca, 1992

10. MILLER, W.C. The Biochemistry of Exercise and Metabolic Adaptation. Brown and Benchmark, USA, 1992.

11. WILLIANS, C. \& DEVLIN, J.T. Foods, nutrition and sports performance. E\&FN Spon, Londres, 1992.

12. PEREIRA, José Gomes. Nutrição, metabolismo energético e ajudas ergogênicas. [on line] Disponível na Internet via www.URL:http//www.aptn.pt/artigos.com.br Arquivo capturado em 10 de Setembro de 2002.

13. CREATINA. [on line] Disponível na Internet via www.URL: http//www.eps.ufsc.com.br. Arquivo capturado em 10 de Setembro de 2002

14. DALL'AGNOL, Tatyana M. Creatina. [on line] Disponível na Internet via www.URL: http//www.maratona.com.br. Capturado em 28 de Setembro de 2002.

15. CREATINA. [on line] Disponível na Internet via www.URL: http//www. usuários.unicor.com.br. Arquivo capturado em 04 de Outubro de 2002.

16. CREATINA. [on line] Disponível na Internet via Www.URL: http//www.aneid.pt/creatine. Arquivo capturado em 04 de Outubro de 2002.

17. CREATINA. [on line] Disponível na Internet via Pubmed: indexed Medline. J Am Pharm Assoc (1999/Nov-Dec); 39(6): 803-10. Arquivo capturado em 12 de Outubro de 2002.

18. MENDES,M;TIRAPEGUI,J. Considerações sobre exercício físico, creatina e nutrição. Revista Bras. Ciências Farm.1999; 35;195-209.

19. GOMES, M;TIRAPEGUI,J. Relação entre alguns suplementos nutricionais e desempenho físico. Arch Latinoam Nutr. 2001; 51; 317-329. 
20. MUJIKA,I; CHATARD,J.C; LACOSTE,L; BARALE,F; GEYSSANT,A. Creatine supplementation does not improve sprint performance in competitive swimmers. Med. Sci. Sports Exercise. 1997; 28; 1435-1440.

21. CLARK,J.F. Creatine and phosphocreatine: a review of their use in exercise and sport. J. Athletic training. 1997; 32; 45-51.

22. GUEDES JR., Dilmar Pinto. A Revolução da Creatina. [on line] Disponível na Internet via www.URL: http//www.viasantos.com. Arquivo capturado em 10 de Outubro de 2002.

23. MACEDO, Vanessa. Creatina $X$ Aumento de Peso Corporal. [on line] Disponível na Internet via www.URL: http//www.totalsport..com.br. Arquivo capturado em 10 de Outubro de 2000.

24. CREATINA. [on line] Disponível na Internet via Pubmed : indexed Medline. J Am Pharm Assoc (1998/Oct); 9(3): 501-13. Arquivo capturado em 12 de Outubro de 2002.

25. CREATINA. [on line] Disponível na Internet via www.URL: http//www.provale.com.br. Arquivo capturado em 15 de novembro de 2000.

26. JACOBS, I. Dietary creatine monohydrate supplementation. Can J Apply Physiol. 1999 Dec; 24(6):503-14

27. MARGHAUN, R.J. Creatine supplementation and exercise performance. Int J Sport Nutr. 1995 Jun; 5(2):94-101

28. STRAUSS, G. In three pro sports teams say "no" to creatine. USA Today, 4 June: News,1 A, 1998.

29. TOLER,S.M. Creatine is an ergogenic for anaerobic exercise. Nutr Rev.1997 Jan; 55(1):21-3.

30. CORDAIN, L. Does creatine supplementation enhance athletic performance? J Am Coll Nutr. 1998 Jun; 17(3):205-206. 
31. ONTIVEROS, M.L.;WALLIMANN,T. Creatine supplementation in health and disease. Moll Cel Biochem. 1998; 184: 427-437. 